\title{
“OLHAR, ENXERGAR E VER: DESAFIOS NO ATO DE PLANEJAR”
}

\section{Severino Ramos dos Santos Maia ${ }^{1}$ e Mídiã Maria de Medeiros ${ }^{2}$}

${ }^{1}$ Especialista no Ensino da Geografia (UFRN), Professor substituto do CEFET-RN, Professor da Rede Publica Estadual e Professor do Colégio Objetivo de Natal/RN; severinomaia@click21.com.br

${ }^{2}$ Diretora Pedagógica do CEAMI - Centro de Estudos e aplicação das Múltiplas Inteligências, Coordenadora Pedagógica do Colégio Objetivo de Natal/RN; midiammedeiros@bol.com.br

Recebido em agosto 2004 e Aceito em abril de 2005

\begin{abstract}
RESUMO
Com a consciência da importância do papel da escola no processo de transformação social, e conseqüentemente da sua atuação na sociedade, contando ainda, com a participação da comunidade escolar e das práticas profissionais fomos dando corpo, forma e identidade ao que pensamos sobre autonomia na escola e que o instrumento ideal para que este papel se consolide é o Projeto Político-Pedagógico. Denominamos este artigo como "Olhar, Enxergar e Ver: Desafios no ato de Planejar" numa alusão filosófica e abstrata às dificuldades impostas pela nossa cultura ao planejamento. No entanto, estas dificuldades não devem ser aquilo que impossibilite uma ação eficaz através do planejamento. Este artigo tem a intenção de mostrar que através de um planejamento estratégico, bem articulado, com idéias bem definidas e representativas dos desejos da comunidade escolar, é possível enxergar uma escola exercendo o seu verdadeiro papel: o de transformar a realidade para uma vida melhor, mais digna.
\end{abstract}

Palavras chave: Educação - Planejamento - Projeto Político Pedagógico

\section{“MIRAR, OBSERVAR Y DESAFIOS EN EL ACTO DE PLANEAR”}

\section{RESUMEN}

Teniendo conciencia de la importancia del papel de la escuela en el proceso de transformación social, y consecuentemente en su prática en la sociedad, contamos com la participación de la comunidad escolar y de las prácticas profesionales, consiguiendo dar cuerpo, forma e identidad a lo que pensamos sorb autonomia en la escuela; y que el instrumento ideal para que este papel se consolide es el proyecto político-pedagógico. Denominamos este artículo "Mirar, Observar y Ver: Desafios en el acto de planear” por una alusión filosófica y abstracta a las dificultades impuestas por nuestras cultura al planeamiento. Sin embargo, estas dificultades no deben ser las que imposibiliten una accción eficaz através del planeamiento.Este artículo tiene la intencíon de mostrar que através de un planeamiento estratégico, bien preparado com ideas bien definidas y representativas de los deseos de la comunidade escuelar, es posible ver una escuela ejerciendo su verdadero papel : el de transformar la realidade para una vida mejor, más digna.

Palabras llave: Educación - Planeamiento - Proyecto Político Pedagógico. “OLHAR, ENXERGAR E VER: DESAFIOS NO ATO DE PLANEJAR” 


\section{INTRODUÇÃO}

Com o objetivo de contribuir com o rompimento das estruturas sócio-educacionais vigentes tão excludentes, cruéis, marcadas, principalmente, pela injustiça social e pela desigualdade social estabelecida pelas políticas do poder constituído, elaboramos este artigo que considera todas as leituras e experiências adquiridas no percurso acadêmico e profissional, após vivências e oportunidades que nos possibilitaram vislumbrar, através de um estudo científico, uma minimização, senão uma ruptura desse sistema sócio-políticoeconômico atrelado ao neoliberalismo.

Tendo ainda a consciência da importância do papel da escola no processo de transformação social, visto que as instituições de ensino, são fundamentais para a formação do cidadão e, conseqüentemente, da sua atuação na sociedade, contando ainda, com a participação da comunidade escolar e da prática profissional, fomos dando corpo, forma e identidade ao que pensamos sobre autonomia na escola e que o instrumento ideal para que este papel se consolide é o Projeto Político-Pedagógico.

O desafio estava em fazer com que os profissionais envolvidos percebessem a necessidade da construção de uma Proposta Político-Pedagógica e que este empreendimento garantiria a construção da unidade, identidade, pensamento único, dinamismo, aprendizagem eficaz, elementos indispensáveis para que a escola seja referência efetivando assim a cidadania, respaldado pelo conhecimento científico.

A utopia de contribuir para uma vida com dignidade, através dos mecanismos da escola, foi à mola mestra que nos impulsionou a construir este trabalho. Nele estão explícitos pensamentos, idéias e ações transformadoras visando a quebra de um sistema opressor no afã de construir uma sociedade mais justa, igualitária, humana e principalmente, mais feliz.

Com a comprovação, por já ter experimentado In loco a construção de uma Proposta Político-Pedagógica, e com a sensibilidade de perceber que esta é uma possibilidade para a consistência da autonomia da escola é que vislumbramos, com este artigo contribuir para esta transformação.

Denominamos este artigo como “Olhar, Enxergar e Ver: Desafios no ato de Planejar” numa alusão filosófica e abstrata às dificuldades impostas pela nossa cultura ao planejamento. No entanto, estas dificuldades não devem ser o que impossibilite uma ação eficaz através do planejamento.

Aos leitores e apreciadores, este artigo tem a pretensão de fomentar uma mobilização na instituição pesquisada e demais pessoas a quem interessar, para perceber, que através de um planejamento estratégico, bem articulado, com idéias bem definidas e representativas dos desejos da comunidade escolar, comprometido com as mudanças sociais, necessidade urgente para este modelo sócio-econômico atual, é possível enxergar uma escola exercendo o seu verdadeiro papel: o de transformar a realidade para uma vida melhor, mais digna.

\section{OLHAR, ENXERGAR E VER: DESAFIOS NO ATO DE PLANEJAR.}


Em pleno século XXI, num mundo marcado pelo processo de globalização cultural e econômica, em meio a uma significativa evolução científica e tecnológica, encontra-se uma realidade nauseante, contrastante. Uma era marcada pela pobreza, injustiça e opressão. Com este modelo sócio-econômico não podemos mais conceber um planejamento educacional macro que não vislumbre, em sua essência, um compromisso com a transformação, uma ruptura com este modelo social excludente e cruel em busca de uma justiça que possa promover senão uma igualdade, mas que minimize este abismo social.

A desigualdade social existente atrofia o crescimento do cidadão, enquanto membro constituinte de uma sociedade. O sistema sócio-econômico vigente impede que este mesmo cidadão exerça seus direitos, se aproprie do conhecimento científico, requisito básico para uma mudança de paradigmas, condição mínima para exercer sua cidadania e, conseqüentemente, uma vida digna.

Impotente, diante desse panorama sócio-político-econômico, falta a este homem condições para digerir essa organização social globalizada sentindo-se assim frustrado a cada tentativa de mudança, sem conseguir o que deseja - uma vida com qualidade. Partindo dessa concepção de fragilidade diante das situações da vida, este mesmo homem, sem as condições para discernir até mesmo o que é melhor pra ele, embarca em condições de extrema submissão, por não ter claro, o seu verdadeiro papel de cidadão.

É contra essa realidade que, o planejamento educacional, instrumento que possibilita, dependendo da forma como é pensado e idealizado, promova ações que encaminhem direcionamentos numa perspectiva de mudar este quadro tão caótico, uma vez que, é neste ambiente onde as classes menos favorecidas encontram oportunidades de ascensão e mobilidade pessoal e social, um caminho para se minimizar este abismo social.

Pensando num planejamento que contemple essa ruptura, é imprescindível que todas as ações deste planejamento, que consideramos promotor de autonomia para a escola e transformador social, desde que tenha imbuído, em sua essência, a idéia de mudança, concorra para a minimização da injustiça e a desigualdade social. Pensando sobre a convergência de pensamentos para uma efetiva transformação gerada pelo planejamento MELLO propõe:

O grande desafio da nova qualidade de ensino será garantir a eqüidade nos pontos de chegada. No entanto, essa eqüidade não se atingirá partindo de propostas $e$ ordenamentos homogêneos e sim de práticas escolares $e$ modelos de gestão construídos em nível local, que permitam incorporar as necessidades desiguais e trabalhar sobre elas ao longo do processo de escolaridade de modo a assegurar acesso ao conhecimento e satisfação das necessidades básicas de aprendizagem para todos. (1993,p. 20)

Nessa premissa, é perceptível que estamos tratando aqui de um planejamento educacional onde todos os membros da comunidade escolar estejam envolvidos. Participem, opinem e estejam comprometidos com as metas a serem atingidas. Nessa dimensão, acreditando na utopia, esperamos que os sonhos dessa gerência sejam comuns: 
uma sociedade mais justa, mais igualitária, mais humana e que os atores envolvidos sejam contemplados com as benesses que as políticas implementadas por essa administração tragam, ou seja, propiciem resultados eficazes do ponto de vista da cidadania.

Verificamos em nossa pesquisa que até existe um desejo de fazer a escola diferente, no entanto, percebemos que falta conhecimento, estudo sobre como se fazer uma Proposta que contemple um fazer didático-pedagógico que promova a satisfação de aprender, que promova uma ruptura com a mesmice e a exclusão social, a ausência de um compromisso profissional com o verdadeiro papel de educador, impedem que se efetive um planejamento participativo comprometido com as mudanças sociais.

Quando está em questão o desejo de mudança é inquestionável o desafio. Partindo desse princípio, nos propomos, através deste artigo, a apresentar a possibilidade de um planejamento educacional consistente se opondo aos obstáculos impostos pela nossa cultura do improviso, do cumprimento de tarefas.

Todas as ações desenvolvidas no planejamento devem ter como sustentáculos, estratégias políticas e sensibilidade. Com essa postura de valorização às decisões e sentimentos, acreditamos que, inicialmente, seja necessário, além do desejo de mudança, um olhar, para que nesta direção se estabeleçam os vínculos ideais para uma tomada de decisão. Quando este olhar é dirigido como um “detector de metais” ele possivelmente perceberá que determinados encaminhamentos contribuirão para o sucesso da instituição e de todos os envolvidos no planejamento.

Este momento do planejamento refere-se ao que VASCONCELLOS denomina de Marco Referencial.

O Marco Referencial é a tomada de posição da instituição que planeja em relação à sua identidade, visão de mundo, utopia, valores, objetivos, compromissos. Expressa o 'rumo', a direção que a instituição escolheu, fundamentado em elementos teóricos da filosofia, das ciências, da fé. Implica, portanto, opção e fundamentação.

Em nome dessa realidade investigada, ainda pudemos perceber que já existe este olhar na escola, embora por circunstâncias que atualmente permeiam as instituições educacionais como: exigência das secretarias de educação, para sistematizar o Plano de Desenvolvimento da Escola - PDE, o Ministério da Educação e viabilizar as verbas, a nova Lei de Diretrizes e Bases. No entanto, verificamos que a necessidade deve existir pela sua real essência: um instrumento teórico-metodológico que promova mudanças na realidade existente.

Pois bem, percebido o ambiente, nós propomos mais uma etapa do planejamento: o enxergar. Nesta fase, o pensamento se aprofunda e buscamos enxergar encaminhamentos para a solução dos problemas detectados pelo olhar. Se fôssemos metaforizar este momento do plano poderíamos denominar "o metal foi detectado e agora, vamos classificá-lo: a que categoria pertence, como vamos trabalhar com ele?” GANDIN apresentando as etapas do planejamento refere-se assim:

(...) Para o planejamento participativo, o diagnóstico é a intermediação entre a proposta ideal, do sonho, e a proposta prática. Nesse sentido, o diagnóstico é um juízo continuado 
sobre a prática, para verificar a distância em ela está do ideal estabelecido em seu referencial. No planejamento participativo, o plano não começa com um diagnóstico, mas com um referencial. (1999, p. 48)

Consideramos, para efeito de sistematização, o processo do diagnóstico contínuo por ser o planejamento, aqui defendido, avaliado a cada etapa executada.

Com estes elementos selecionados: o olhar e o enxergar, vamos então, ao terceiro desafio do ato de planejar com participação, com adesão, com credibilidade nas mudanças benéficas que ele pode promover: o ver No início da pesquisa apresentamos a equipe pedagógica as possibilidades de crescimento da organização através de um planejamento que contemplasse estas características, a adesão e o crédito foi alterado, continuamos apresentando a terceira etapa: a Programação, denominação defendida por VASCONCELLOS; 'O Projeto Político-Pedagógico é composto, basicamente, de três grandes partes, articuladas entre si: Marco Referencial, Diagnóstico, e Programação”. (2000, p. 170)

Configuramos, então, o ver como a Programação. Esta etapa é caracterizada como a tomada de decisão, a construção do projeto que viabilizaria as mudanças expressa no sonho das transformações sociais. Nesta estação, seria o momento de a partir das leituras que conseguimos fazer a respeito da sociedade que temos e a que sonhamos ter, definir políticas e estratégias que possibilitem a realização do plano.

Ainda nesta terceira fase, por ser a estação onde será demandado mais tempo, é preciso que, a equipe gerencial do processo, determine o período necessário para a execução do plano que pode ser a curto ou longo prazo, dependendo das metas que se deseja alcançar.

A Programação, dentro de um plano, é uma proposta de ação para diminuir a distância entre a realidade da instituição que planeja e o que estabelece o Marco Referencial. Dito de outra forma, "é a proposta de ação para sanar (satisfazer) as necessidades apresentadas pelo Diagnóstico”. (GANDIN, 1991, p. 45).

Reiteramos, neste documento a importância para este momento, pois pelo fato de ser a operacionalização o momento que demanda maior tempo, considerando para isso que mudar a realidade não é muito simples assim, esta é a parte que exige todo um rigor metodológico para que se efetivem as ações.

VASCONCELLOS diz: "A ação da instituição é fundamental, pois ela é que dá vida, consistência, o seu sentido de existir. O problema que se coloca é o tipo e a qualidade da ação que irá se desenvolver. Precisamos chegar a uma ação que seja de fato significativa para a instituição, o que significa dizer uma ação possível e que atenda suas reais necessidades". (2000. p. 194).

Concluímos nosso artigo afirmando que, priorizando, referendado por estas orientações, um olhar, representado conceitualmente pelo Marco Referencial; um enxergar, Diagnóstico; o ver, a Programação; a equipe gerencial do planejamento participativo experimenta o sabor de uma ação eficaz a partir de uma vivência democrática contribuindo com a ampliação das competências humanas, assim como, a possibilidade de transformar a realidade. 
Propomos como ação eficaz o desenvolvimento de ações elegendo como eixo norteador, a cidadania, por acreditarmos no desenvolvimento do homem/mulher partindo do princípio que, como ser social que somos, devemos aprender a conviver e esta convivência deve ser a mais harmoniosa possível, isto sem perder de vista a capacidade de pensar e tomar decisões coletivas em benefício da coletividade.

A cidadania em foco na nossa proposta significa dizer que as ações expressas devem ter como reta de chegada o homem em sua plenitude. Com a competência de atuar, opinar, participar, tomar decisões, lutar pelos direitos conquistados. Isto posto, todos os encaminhamentos, abordagens, atitudes e posturas da escola devem estar contemplados em seu planejamento e em sintonia coma sua direção maior: o homem/mulher cidadão.

Assim por considerarmos este homem com uma capacidade de atuar e modificar essa estrutura social excludente e desigual é que, na instituição pesquisada, priorizamos uma proposta caracterizada, principalmente, pela ruptura e transformação.

Gostaríamos de finalizar com um trecho muito sábio de NEVES que demonstra nossa expectativa em relação à educação brasileira.

O Brasil e a educação brasileira tentam começar um novo tempo, uma nova história na qual a autonomia é um dos símbolos de liberdade, de uma cidadania mais participativa e da verdadeira democracia.NEVES. (1995, P.127)

\section{BIBLIOGRAFIA}

GANDIN, Danilo. GANDIN, Luís Armando. Temas para um projeto político pedagógico. Petrópolis, RJ: Vozes, 1999.

MELLO, Guiomar Namo de. Autonomia da escola: Possibilidades, limitações e condições. In: Cadernos Educação Básica - Série Atualidades Pedagógicas, Brasília, MEC, 1993, vol.1.

NEVES, Rui (1995). Os Professores e os Programas de Educação Física Representações e Atitudes. Dissertação de Mestrado. Faculdade de Ciências do Desporto e Educação Física - Universidade do Porto.

VASCONCELlOS, Celso dos Santos. Planejamento: Projeto de Ensino Aprendizagem e Projeto Político-Pedagógico - elementos metodológicos para elaboração e realização. São Paulo: Libertad,2000.

VEIGA, Ilma Passos Alencastro. (org.) Projeto político-pedagógico da escola: Uma construção possível. Campinas, SP: Papirus, 1995. 